\title{
Potential climate change impacts on the water balance of subcatchments of the River Spree, Germany
}

\author{
I. Pohle ${ }^{1}$, H. Koch ${ }^{2}$, and U. Grünewald ${ }^{1}$ \\ ${ }^{1}$ Chair of Hydrology and Water Resources Management, Brandenburg University of Technology Cottbus, \\ Konrad-Wachsmann-Allee 6, 03046 Cottbus, Germany \\ ${ }^{2}$ Potsdam Institute for Climate Impact Research: Climate Impacts and Vulnerabilities, Telegrafenberg A62, \\ 14473 Potsdam, Germany
}

Correspondence to: I. Pohle (ina.pohle@ @u-cottbus.de)

Received: 30 January 2012 - Revised: 31 July 2012 - Accepted: 4 November 2012 - Published: 11 December 2012

\begin{abstract}
Lusatia is considered one of the driest regions of Germany. The climatic water balance is negative even under current climate conditions. Due to global climate change, increased temperatures and a shift of precipitation from summer to winter are expected. Therefore, it is of major interest whether the excess water in winter can be stored and to which extent it is used up on increasing evapotranspiration.

Thus, this study focuses on estimating potential climate change impacts on the water balance of two subcatchments of the River Spree using the Soil and Water Integrated Model (SWIM). Climate input was taken from 100 realisations each of two scenarios of the STatistical Analogue Resampling scheme STAR assuming a further temperature increase of $0 \mathrm{~K}$ (scenario A) and $2 \mathrm{~K}$ by the year 2055 (scenario B) respectively. Resulting from increased temperatures and a shift in precipitation from summer to winter actual evapotranspiration is supposed to increase in winter and early spring, but to decrease in later spring and early summer. This is less pronounced for scenario A than for scenario B. Consequently, also the decrease in discharge and groundwater recharge in late spring is lower for scenario A than for scenario B. The highest differences of runoff generation and groundwater recharge between the two scenarios but also the highest ranges within the scenarios occur in summer and early autumn. It is planned to estimate potential climate change for the catchments of Spree, Schwarze Elster and Lusatian Neisse.
\end{abstract}

\section{Introduction}

During the past decades a decrease in summer rainfall, an increase in winter precipitation and an increase in temperature in all seasons, especially in winter, has been observed for Germany (Schönwiese et al., 2006) and more detailed for Saxony (Franke et al., 2004). Further studies about potential climate impacts on the water balance of river catchments in Brandenburg and Saxony (Gerstengarbe et al., 2003; Wegehenkel and Kersebaum, 2009; Hattermann et al., 2008) found a decreasing climatic water balance and water yield in the region. Due to temperature increase, higher potential evapotranspiration can be expected, e.g. caused by a longer vegetation period. Likewise, this results also in higher actual evapotranspiration unless limited by water yield. Changes in precipitation and temperature both cause changes in runoff generation and river discharge; even small changes can highly affect groundwater recharge (Arnold et al., 1993).

In this study the semi-distributed process-based ecohydrological model SWIM (Krysanova et al., 1998) was calibrated and validated for two subcatchments of the River Spree. These models then were used to simulate the reference period 1961-1990 and two climate scenarios assuming a further temperature increase of $0 \mathrm{~K}$ (scenario $\mathrm{A}$ ) and $2 \mathrm{~K}$ (scenario B) until 2055 in the study region. For each scenario 100 realisations of future climate from the regional climate model STatistical Analogue Resampling scheme STAR (Orlowsky et al., 2008) were used. Not only mean values, but especially monthly ranges of water balance components precipitation, actual evapotranspiration, discharge and groundwater recharge were examined. 


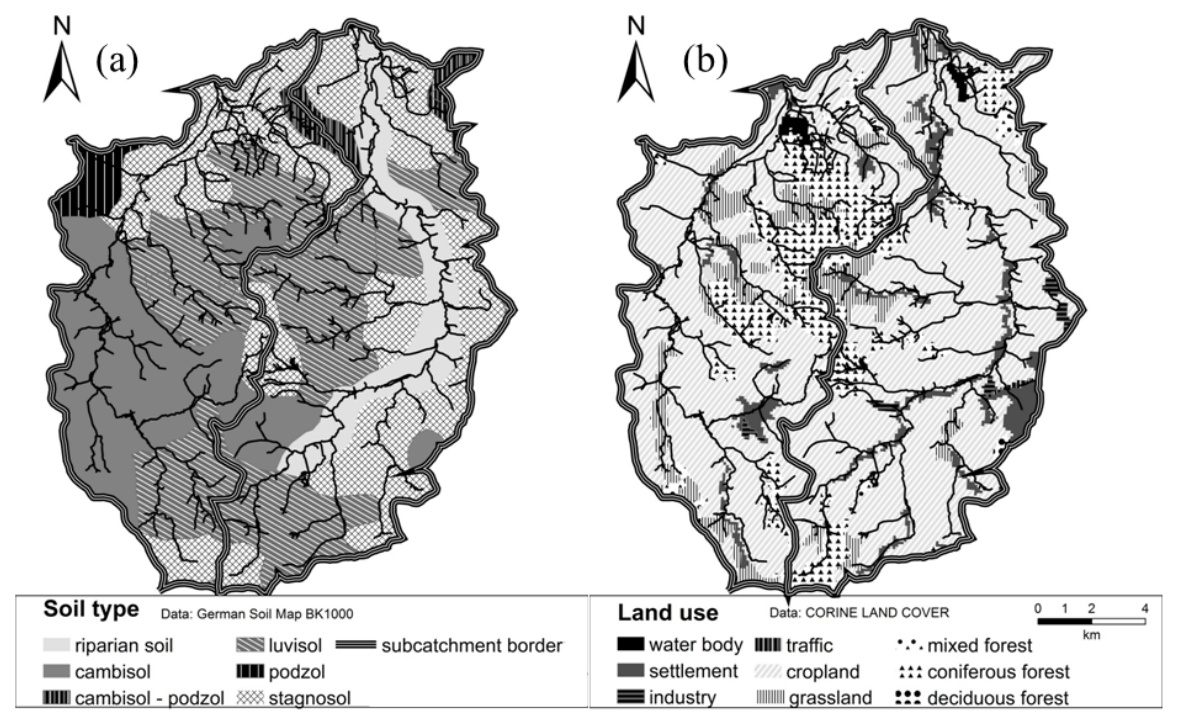

Fig. 1. General maps of the study region: (a) soil map, (b) land use map for the subcatchments of River Schwarzer Schoeps (left) and Weisser Schoeps (right).

\section{Data and methods}

\subsection{Study region}

Lusatia is located in Eastern Germany, more precisely in the south of Brandenburg and in the east of the Free State of Saxony. Its major rivers are the Spree, the Schwarze Elster and the Lusatian Neisse. Due to lignite mining activities the water balance of Lusatia is profoundly disturbed (Grünewald, 2001). Groundwater resources have been reduced by dewatering large areas in order to extract lignite in open cast mines. River discharges have been increased by mine discharges and annual variations have been evened out. Due to those interventions on the hydrological system there is no natural relation between rainfall and runoff. This makes it difficult to calibrate water balance models for larger areas based on observed discharges. Therefore, this study concentrates on two subcatchments of the River Spree without influence of both water management and mining activities: the River Schwarzer Schoeps up to Jaenkendorf gauge $\left(A=115 \mathrm{~km}^{2}\right)$ and the River Weisser Schoeps up to Saerichen gauge $\left(A=135 \mathrm{~km}^{2}\right)$. Both subcatchments are located in the east of Saxony in a hilly area. Long term annual precipitation for both subcatchments is about $650 \mathrm{~mm}$; mean annual temperature is about $8^{\circ} \mathrm{C}$. Dominating soil types are luvisols, cambisols and stagnosols; riparian soils can be found in the floodplain of Weisser Schoeps (Fig. 1a). The dominating land use is cropland (70\%), $15 \%$ of the area is forested, whereby coniferous forests are dominating (Fig. 1b). Grassland accounts for $5 \%$ of the area and settlements $(5 \%)$ mostly stretch along the rivers. Further forms of land use in the area are water bodies, industry and traffic infrastructure.

\subsection{Regional climate model STAR}

Using the STatistical Analogue Resampling scheme STAR time series of climate parameters by resampling segments of daily observations can be created. Simulated time series are forced only by the linear air temperature trend of the future period (Huang et al., 2010). One of the scenarios used in this analysis assumes no further climate change in the study region from now on, but includes a temperature increase of $0.6 \mathrm{~K}$ compared to the reference period because the recent years were already warmer than the reference period (scenario A). The second scenario assumes a further warming of $2 \mathrm{~K}$ until 2055 in the study region (scenario B). Due to the assumed linear temperature trend in scenario $\mathrm{B}$ the mean annual temperature in 2020 is increased by $0.5 \mathrm{~K}$, for the middle of the scenario period the temperature increase is $1.2 \mathrm{~K}$ respectively. A number of 100 realisations were used for 20072055.

\subsection{Hydrological modelling with SWIM}

The semi-distributed process-based eco-hydrological model SWIM (Krysanova et al., 1998) is based on the models SWAT (Arnold et al., 1993) and MATSALU (Krysanova et al., 1989). A detailed model description can be found in (Krysanova et al., 2000). SWIM has been used in various climate impact studies (Hattermann et al., 2004, 2008; Krysanova et al., 2005; Conradt et al., 2012). In this study, 127 hydrotopes for the catchment of the River Weisser Schoeps and respectively 116 for the catchment of the River Schwarzer Schoeps were created from sub-basin, soil and land use maps. Daily climate data from six surrounding climate stations are interpolated by kriging to the centroid of 


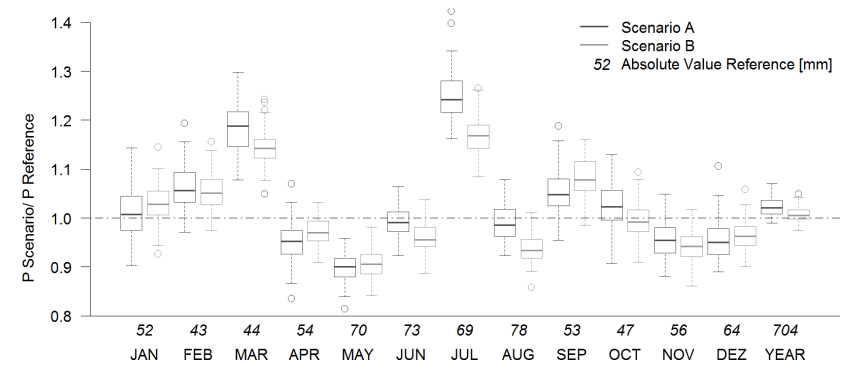

Fig. 2. Ratio between precipitation $(P)$ of the scenarios and the reference period, Weisser Schoeps.

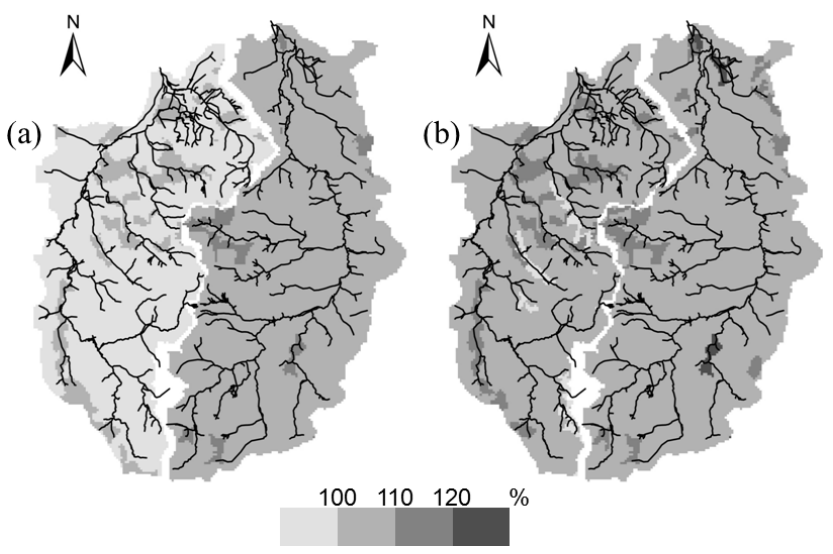

Fig. 3. Ratio between annual actual evapotranspiration for the scenarios and the reference period (a) scenario A, (b) scenario B.

both subcatchments, correcting precipitation by wind. Agriculture is parameterized as a crop rotation dominated by winter wheat as typical of the region; the same crop is calculated for all hydrotopes. The model calibration is done for 20022004 and the validation for 1998-2001 and 2005-2006, respectively, using an identical parameter set for both subcatchments. As the general hydrograph but especially flow volumes and low flow periods are of interest in this study, the model performance is evaluated using the Nash-Sutcliffe model efficiency coefficient NSE (Nash and Sutcliffe, 1970), the Nash-Sutcliffe model efficiency coefficient with logarithmic values of observed and simulated daily discharge $\mathrm{NSE}_{\log }$, the relative volume error RVE and Pearson's correlation coefficient $R^{2}$ (Table 1). A satisfying model performance was achieved for both catchments (Table 1). Water balance components simulated for observed climate data of the standard normal period (1961-1990) as reference period were compared to those simulated for the scenario period 2020-2055.

\section{Results and discussion}

For illustration purposes, Fig. 2 shows the ratio between precipitation $(P)$ for the scenarios and the reference period for the Weisser Schoeps catchment. The box plot visualizes both

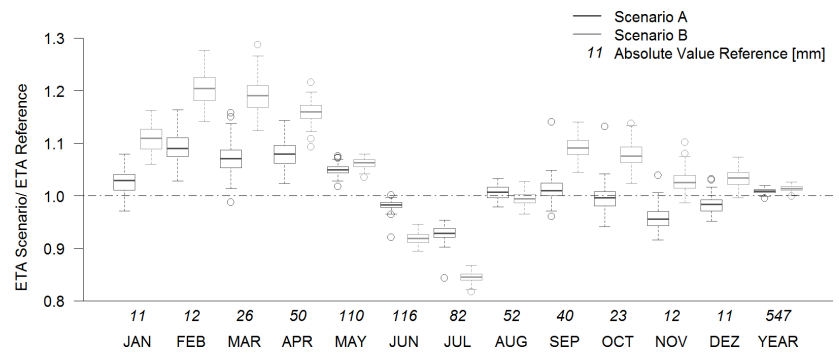

Fig. 4. Ratio between actual evapotranspiration (ETA) for the scenarios and the reference period, Weisser Schoeps.

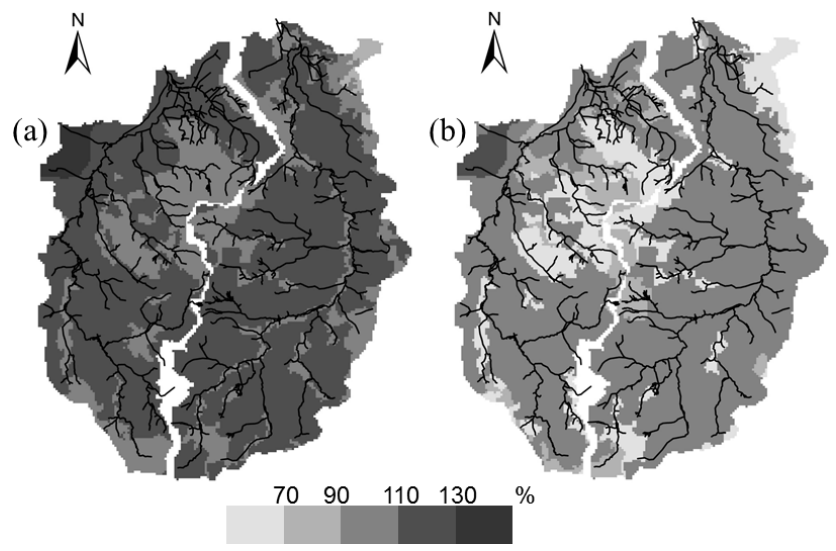

Fig. 5. Ratio between annual runoff generation for the scenarios and the reference period (a) scenario A, (b) scenario B.

long term median for all realisations of each scenario and the range of 100 realisations. For the annual sum, there was no significant change in precipitation for both scenarios; also the range was relatively small but still wider for scenario A than for scenario B. Mean monthly precipitation in the scenarios was lower than in the reference in April, May, June, August, November and December. For scenario B the reduction in November was higher than for scenario A and there was a reduction in August as well. In March and July mean precipitation was increased especially for scenario A, whereas in September the increase was lower in the scenario A than in the scenario B. Actual evapotranspiration increased for both scenarios compared to the reference, especially for the catchment of Weisser Schoeps and for forests and grassland (Fig. 3). Despite only slight changes in annual actual evapotranspiration for both scenarios, the effects became clearer on a monthly scale (Fig. 4). In spring, increases for scenario $\mathrm{A}$ on average by $10 \%$ and for scenario $\mathrm{B}$ by $20 \%$ were caused by an increase in temperature and an earlier start of the vegetation period. Large ranges of actual evapotranspiration can be explained by large temperature ranges in the scenarios. In summer, actual evapotranspiration decreased by up to $10 \%$ for scenario A and even more for scenario B in June and July due to constrained water yield. Hence, ranges were rather low. In autumn, actual evapotranspiration did not 
Table 1. Quality criteria for model calibration and validation.

\begin{tabular}{llrrrr}
\hline Subcatchment & Period & NSE & NSE $_{\log }$ & RVE [\%] & $R^{2}$ \\
\hline Schwarzer Schoeps, & Calibration & 0.74 & 0.72 & 1.7 & 0.76 \\
Jaenkendorf & Validation & 0.71 & 0.62 & -4.4 & 0.71 \\
\hline Weisser Schoeps, & Calibration & 0.62 & 0.77 & 2.1 & 0.65 \\
Saerichen & Validation & 0.66 & 0.64 & 0.5 & 0.71
\end{tabular}

change much for scenario A, but increased for scenario B due to a higher temperature increase. Runoff generation for scenario A was higher than for the reference in almost all hydrotopes, but mostly lower for scenario B (Fig. 5). For forest and grass land it did not change for scenario $\mathrm{A}$, but significantly decreased for scenario B resulting from higher actual evapotranspiration. Figure 6 shows that for both scenarios increasing discharges were simulated for late summer, autumn and winter with highest ratios in July and September (about $25 \%$ or more increase). A slight decrease of discharge was simulated for May and June with higher effects for scenario B. Higher discharges in autumn might be caused by higher precipitation in July and September. Lower discharges in May and June were caused by declining climatic water balance in those months. Groundwater recharge increased for scenario A in most areas, but decreased in grassland areas (Fig. 7). For scenario B a decrease occurred especially on forest and grassland. During the year, groundwater recharge was decreased by up to $10 \%$ for scenario A and somewhat more for scenario B on average. Decreasing groundwater recharge can be explained with lower water availability which is caused by higher actual evapotranspiration in spring. The changes during the months had the same tendency as those in runoff; only the percentage of decrease was higher (Fig. 8). In May and June water availability was lowest, so groundwater recharge reached a minimum and the highest decrease occured (about $-50 \%$ ). Groundwater recharge in September increased due to higher precipitation in this month and just slightly increased actual evapotranspiration. All in all, groundwater recharge is the smallest water balance component in the study region, hence small differences in total numbers can cause high numbers in percentage deviation.

\section{Conclusion and outlook}

Climate impacts on water balance components of the two subcatchments examined differed on a spatial scale but were rather equal on a temporal scale. For scenario A slightly increasing precipitation compensated the effects of increasing actual evapotranspiration due to temperature increase for the whole year compared to the reference period. Both river discharges and groundwater recharge slightly increased compared to the reference period. In scenario B no significant precipitation trend occurred for the whole year. However, in

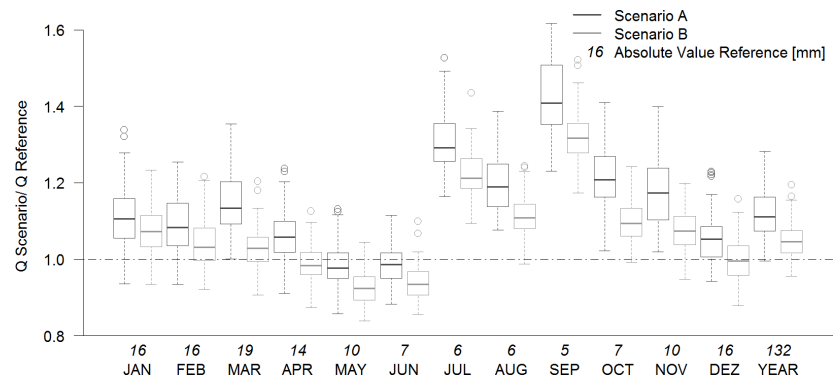

Fig. 6. Ratio between discharge $(Q)$ of the scenarios and the reference period, Weisser Schoeps.

combination with higher actual evapotranspiration the water availability was reduced. The river discharge increased for the whole year, while groundwater recharge decreased. Decreased water availability in June and July might cause water stress. Both ranges and differences of the water balance components were much higher on a monthly basis than for the whole year. The highest differences between the two scenarios and the reference period as well as the highest ranges within the scenarios were noticed in summer and early autumn. The ranges of all water balance components were higher for scenario A than for scenario B. Seasonality of land use as well as soil type affected climate impact on spatial scale.

Uncertainties in this study can be found both in the hydrological modelling and in the climate model itself. For the hydrological model uncertainties can be found in the input values, like discharge measurements and also soil and land use data. Additionally, measured discharges may not only result from a natural rainfall - runoff relationship, but may also be affected by anthropogenic influences such as pond fishery. In hydrological modelling, there is often the risk of achieving similar results with different parameter sets due to equifinality. In order to reduce the risk of equifinality, independent calibration and validation periods are chosen, both including dry and wet years. As two subcatchments, which are similar in most of their characteristics such as topography, land use and soil, achieve satisfactory performance for several criteria using the same parameter set, the risk of equifinality is reduced. Uncertainties in the climate model cannot be accounted for in this paper. The question is not "how will the future be like", but how the potential climate change impacts the water balance assuming STAR scenarios A and B using 100 realisations each. The high bandwidth in long term monthly means of these 100 realisations of the two scenarios shows a high range of potential climate change impacts. For individual years, the water balance components might be outside of that bandwidth even.

This study focused on estimating potential climate change impacts assuming STAR scenarios A and B for two subcatchments of the River Spree. In order to reduce uncertainty and to increase the bandwidth of possible future climate, further 
climate scenarios should be included. It is planned to enlarge the study area for the Lusatian parts of the catchments of Spree, Schwarze Elster and Lusatian Neisse. As various land use changes are expected in that region, also land use change impact studies are to be conducted.

Acknowledgements. The authors acknowledge the International Graduate School at Brandenburg University of Technology for funding. Measured discharge data for the study region were delivered by Sächsisches Landesamt für Umwelt, Landwirtschaft und Geologie.

Edited by: K. Schneider and S. Achleitner

Reviewed by: K. Drastig and one anonymous referee

\section{References}

Arnold, J. G., Allen, P. M., and Bernhardt, G.: A comprehensive surface-groundwater flow model, J. Hydrol., 142, 47-69, doi:10.1016/0022-1694(93)90004-s, 1993.

Conradt, T., Koch, H., Hattermann, F., and Wechsung, F.: Spatially differentiated management-revised discharge scenarios for an integrated analysis of multi-realisation climate and land use scenarios for the Elbe River basin, Reg. Environ. Change, 12, 633-648, doi:10.1007/s10113-012-0279-4, 2012.

Franke, J., Goldberg, V., Eichelmann, U., Freydank, E., and Bernhofer, C.: Statistical analysis of regional climate trends in Saxony, Germany, Clim. Res., 27, 145-150, doi:10.3354/cr027145, 2004.

Gerstengarbe, F.-W., Badeck, F., Hattermann, F. F., Krysanova, V., Lahmer, W., Lasch, P., Stock, M., Suckow, F., Wechsung, F., and Werner, P. C.: Studie zur Klimatischen Entwicklung im Land Brandenburg bis 2055 und deren Auswirkungen auf den Wasserhaushalt, die Forst- und Landwirtschaft sowie die Ableitung erster Perspektiven, PIK, Potsdam, 2003.

Grünewald, U.: Water resources management in river catchments influenced by lignite mining, Ecol. Eng., 17, 143-152, 2001.

Hattermann, F. F., Krysanova, V., Wechsung, F., and Wattenbach, M.: Integrating groundwater dynamics in regional hydrological modelling, Environ. Modell. Softw., 19, 1039-1051, doi:10.1016/j.envsoft.2003.11.007, 2004.
Hattermann, F. F., Post, J., Krysanova, V., Conradt, T., and Wechsung, F.: Assessment of Water Availability in a Central-European River Basin (Elbe) under Climate Change, Adv. Clim. Change. Res., 4, 42-50, 2008.

Huang, S. C., Krysanova, V., Osterle, H., and Hattermann, F. F.: Simulation of spatiotemporal dynamics of water fluxes in Germany under climate change, Hydrol. Process., 24, 3289-3306, doi:10.1002/hyp.7753, 2010.

Krysanova, V., Meiner, A., Roosre, J., and Vasilyev, A.: Simulation modeling of the coastal waters pollution from agricultural watershed, Ecol. Model., 49, 7-29, doi:10.1016/0304-3800(89)900410, 1989.

Krysanova, V., Müller-Wohlfeil, D. I., and Becker, A.: Development and test of a spatially distributed hydrological water quality model for mesoscale watersheds, Ecol. Model., 106, 261-289, 1998.

Krysanova, V., Wechsung, F., Arnold, J., Srinivasan, R., and Williams, J.: SWIM (Soil and Water Integrated Model) User Manual, Potsdam Institute for Climate Impact Research, Potsdam, 239 pp., 2000.

Krysanova, V., Hattermann, F. F., and Habeck, A.: Expected changes in water resources availability and water quality with respect to climate change in the Elbe River basin (Germany), Nord. Hydrol., 36, 321-333, 2005.

Nash, J. E. and Sutcliffe, J. V.: River Flow Forecasting Through Conceptual Models - Part I - A Discussion of Principles, J. Hydrol., 10, 282-290, 1970.

Orlowsky, B., Gerstengarbe, F.-W., and Werner, P. C.: A resampling scheme for regional climate simulations and its performance compared to a dynamical RCM, Theor. Appl. Climatol., 92, 209-223, 2008.

Schönwiese, C.-D., Staeger, T., and Troemel, S.: Klimawandel und Extremereignisse in Deutschland, Offenbach, 7-17, 2006.

Wegehenkel, M. and Kersebaum, K. C.: An assessment of the impact of climate change on evapotranspiration, groundwater recharge, and low-flow conditions in a mesoscale catchment in Northeast Germany, J. Plant Nutr. Soil Sc., 172, 737-744, doi:10.1002/jpln.200800271, 2009. 